\title{
P178 INVESTING IN A WEEKLY LOTTERY - DOES IT WORK?
}

Ruth Freeman The Myton Hospices, Warwick, UK

10.1136/bmjspcare-2011-000105.178

Investing in a weekly lottery can seem like a significant financial risk for a small to medium sized hospice and paying an external canvassing company to recruit members a step too far. In this time of economic insecurity, however, Lottery continues to be a very attractive and affordable fundraising proposition for a wide range of donors and is therefore worthy of significant consideration.

The Myton hospices ran a lottery recruitment campaign in 2009 using an external canvassing agency - the target was to recruit 12000 new donors over 12 months, results outlined below

Year 1

Income; £ 574 080, Cost; £ 360 000, net income; $£ 214000$

Year 2

Income; £ 505 191, Cost £ 165 000, net income; £340 191

Attrition

Year $1=8 \%$, Year $2=12 \%$

Predicted net income over 5 years $=£ 1450000$

In addition to the above the increase to the Donor database of 12000 new names has resulted in over $£ 50000$ in Raffle income and $£ 13000$ in donations.

The secret to making a campaign work is as follows;

- Train the external canvassers in - house and to keep them up to date

- Negotiate the recruitment costs with the agency - ensuring that a 3 month "drop out "clause is built in

- Ensure that recruitment costs are phased over the expected life time value of the member / donor, that is, don't pay the full costs up front but make sure that there are anniversary reviews

- Build a solid business case and make sure the Trustees buy in to the campaign! 